\title{
Taguchi Deneysel Tasarım Metodu Kullanılarak Karadon (Zonguldak) Kömürünün Yağ Aglomerasyonu Davranışının İncelenmesi
}

\author{
Selma DÜZYOL ${ }^{* 1}$ \\ ${ }^{1}$ Selçuk Üniversitesi, Mühendislik Fakültesi, Maden Mühendisliği Bölümü, Konya
}

Geliş tarihi: 01.06.2016

Kabul tarihi: 23.11 .2016

$\ddot{O} z$

Ülkeler, sahip oldukları yerli kaynakları kullanarak hem dışa bağımlılıklarını azaltabilir hem de bu bağımlılı̆̆a dayalı ekonomik kayıpların önüne geçebilirler. $\mathrm{Bu}$ düşünce 1 şı̆̆ı altında, ülkemiz kömürlerinin ve özellikle ince boyutta olanlarının en az kayıpla değerlendirilmesi, yeterli bir planlamayı takiben etkin bir uygulama ile mümkündür.

Bu çalışmada ince boyuttaki Karadon (Zonguldak) kömürlerinin yağ aglomerasyonu yöntemi ile zenginleştirilmesi, çeşitli parametreler ışığı altında araştırılmıştır. Deneysel çalışmalar, Taguchi (L16) deneysel tasarım yöntemi kullanılarak planlanmış ve yağ aglomerasyonunun başarısı, elde edilen aglomeratların kül içeriği ve yanabilir kısım verimi $(Y K V)$ ile değerlendirilmiştir. Deneysel tasarım ile farklı şartlar altında 16 adet aglomerasyon deneyi gerçekleştirilmiş, anlam analizi ile optimizasyon çalışmaları neticesinde doğrulama deneyi yapılmıştır. Yapılan analizler neticesinde, 39,48 olan en yüksek sinyal/gürültü $(S / G)$ oranına Test 2 ile ulaşılmış ve bu deneyden elde edilen aglomeratların ortalama $Y K V$ değerinin \%94,2 ile en yüksek olduğu belirlenmiştir. En büyük aglomerat boyutları (ortalama 5-7 mm) Test 16'dan elde edilmiş ancak $Y K V$ değerlerinin düşük olduğu görülmüştür.

Anahtar Kelimeler: Taguchi metodu, Yağ aglomerasyonu, Kömür

\section{Investigation of Oil Agglomeration Behaviour of Karadon (Zonguldak) Coal Using Taguchi Experimental Design}

\begin{abstract}
Countries disposing their own domestic resources may reduce the external dependences as well as they prevent the economic losses caused by this dependency. Under the light of this thought, the beneficiation
\end{abstract}

\footnotetext{
*Sorumlu yazar (Corresponding author): Selma DÜZYOL, selmad@selcuk.edu.tr
} 
Taguchi Deneysel Tasarım Metodu Kullanılarak Karadon (Zonguldak) Kömürünün Yă̆ Aglomerasyonu Davranışının İncelenmesi

of the coal reserves especially fine coals in Turkey with minimum losses is possible only by an effective implementation following a sufficient planning.

The enrichment of Karadon (Zonguldak) fine coal was investigated by the use oil agglomeration process in the light of several parameters throughout the present work. The experimental works were planned by using Taguchi (L16) experimental design and the success of oil agglomeration was evaluated with the ash content and combustible recovery $(C R)$ of the agglomerates obtained. 16 agglomeration tests were realized under different conditions and a confirmation test was performed by the analysis of mean after optimization works completed. The maximum signal/noise $(S / N)$ ratio $(39,48)$ was obtained at Test 2 and the reached average $C R$ of agglomerates was determined as a highest value of $94,2 \%$. In spite of lower $C R$ value, the largest agglomerate size (average 5-7 mm) was obtained from the Test 16.

Keywords: Taguchi method, Oil agglomeration, Coal

\section{GİRIŞ}

Ülkemizde son yıllarda enerji alanında dişa bağımlılığın azaltılması ve doğal kaynakların daha etkin kullanılması ön plana çıkmıştır. Katı yakıtlar içerisinde bulunan kömür, yenilenemeyen doğal kaynaklarımızdan olup üretimi ve tüketiminin etkin yapılması önemlidir. Kömürün maden ocağından üretiminden itibaren piyasanın ihtiyacına göre hazırlanması, eleme, boyut küçültme ve kömür hazırlama işlemlerini içeren birtakım süreçlerden geçirilmektedir. Bu işlemler sırasında fazla miktarda ince boyutta kömür meydana gelmektedir. Mevcut kömür hazırlama tesislerinde bahsedilen ince boyuttaki kömürler, ya atığa karışmakta ya da termik santrallere yakıt olarak verilmektedir. $\mathrm{Bu}$ durumda, özellikle yüksek kalorifik değere sahip olan ince boyuttaki kömürler ekonomik bir kayıp olarak görülmelidir. $\mathrm{Bu}$ nedenle maden ocağında üretiminden başlayarak tüketiciye ulaşıncaya kadar geçen süreçte oluşan ince boyutlu kömürlerin de ekonomiye kazandırılması ayrıca önem arz etmektedir. $\mathrm{Bu}$ kömürlerin ekonomiye yeniden kazandırılabilmesi birtakım tekniklerin uygulanmasıyla mümkündür. İnce boyutlu kömür tanelerinin kazanımında, tane boyutuna bağl1 olarak farklı yöntemler kullanılmaktadır [1-5]. Bu yöntemler arasında sayılan yağ aglomerasyonu, çok ince kömür tanelerine $(5 \mu \mathrm{m})$ [6] rahatlıkla uygulanılabilmesinin yanı sira, tane boyutunun büyütülmesi nedeniyle kazanımın kolay olması ve kömürün kalorifik değerinin de artması bakımından [2] ön plana çıkmaktadır. Yă̆ aglomerasyonu işleminde, hidrofobik özellikteki kömür tanelerinin yağ ile bir araya getirilmesi, dolayısıyla tane boyutlarının büyütülmesi ve sonrasında eleme ile inorganik kısımdan ayrılması söz konusudur [7]. Kömürün tipi, tane boyutu, kullanılan yağın özellikleri, miktarı, katı konsantrasyonu, $\mathrm{pH}$, karıştırma hızı, aglomerasyon süresi gibi pek çok parametre yăg aglomerasyonu yönteminde etkili olmaktadır [8]. Literatürde yağ aglomerasyonu üzerine çok fazla çalışma bulunmakta olup Zonguldak kömürleri üzerinde yapılan yağ aglomerasyonu çalışmaları incelendiğinde;

Ünal ve arkadaşları [9] gazyağı, diesel oil ve Kerkük ham petrolünün Zonguldak kömürünün yağ aglomerasyonunda kullanılabileceğini ve gazyağı miktarının önemli bir parametre olduğunu ifade etmişlerdir. Benzer şekilde, Aktaş [10] kömürün yağ aglomearsyonuna diesel yağ ile çeşitli parametrelerin (yağ miktarı, katı konsantrasyonu, karıştırma hızı ve süresi, $\mathrm{pH}$ ve yüzey aktif madde varlığı) etkisini incelemiştir. Artan yă miktarı ile kazanım artarken karıştırma hızı ve süresinin önemli bir etkisinin olmadığını, süspansiyon pH'ının ise aglomerasyonu etkilediğini belirtmiştir. Cebeci ve arkadaşları [11], gazyağı ile gerçekleştirdikleri diğer bir çalışmada, yağ konsantrasyonu, aglomerasyon zamanı ve çeşitli tuzların etkilerini incelemişler ve en iyi sonuca, gazyağının ağırlıkça \%20 konsantrasyonunda, $\mathrm{pH} 7,5$ ve 15 dakika'lık karıştırma süresinde ulaştıklarını, $\mathrm{FeSO}_{4}, \mathrm{NaCl}$, $\mathrm{FeCl}_{3}$ ve $\mathrm{Al}_{2}\left(\mathrm{SO}_{4}\right)_{3}$ tuzlarından ise yalnıca $\mathrm{NaCl}$ 'nin yüksek konsantrasyonda yanabilir kısım verimine olumlu etkisi olduğunu belirtmişlerdir. 
Cebeci [12] diğer bir araştırmasında ise, aglomerat boyutlarının büyümesinin kinetiğini çeşitli parametreler altında (yağ konsantrasyonu, pülp yoğunluğu, karıştırma hızı) incelemiştir. Cebeci ve Sönmez'in [13] Box-Wilson deneysel tasarım yöntemini kullandıkları diğer bir çalışmalarında ise yağ konsantrasyonu ile karıştırma hızına ilaveten $\mathrm{CaCl}_{2}$ konsatrasyonunun etkisini incelemişler ve temas açısı ile yüzey gerilimi ölçümleri gerçekleştirmişlerdir. Yine yağ miktarı, karıştırma süresi ve hızı, katı konsantrasyonu gibi bazı parametrelerin yağ aglomerasyonuna etkileri Aslan ve Ünal [14] tarafindan modelleme ile araştırılmış ve optimum şartlardaki kömür kazanımının $\% 96,39$ olduğu ifade edilmiştir.

Çok fazla parametrenin etkili olduğu deneysel çalışmalarda, her bir faktörün etkisini belirleyebilmek için çok fazla sayıda deney yapmak gerekmekte ve bu durum hem maliyet hem de zaman açısından olumsuz görülmektedir. Taguchi deneysel tasarım metodu [15], maliyetleri ve harcanan zamanı en düşük seviyede tutmak için en az deney yapma prensibine dayanan yöntemlerden birisidir. Ayrıca, farklı parametrelerin, farklı seviyeleri arasından en iyi kombinasyonu saptamak açısından oldukça kullanışlı olup yapılmamış olan diğer deney sonuçları ile maksimum ve minimum değerler de tahmin edilebilmektedir. $\mathrm{Bu}$ yöntemin diğer istatistiksel deney tasarım yöntemlerinden fark1; bir deneyi etkileyen parametreleri, kontrol edilebilen ve kontrol edilemeyen olmak üzere iki grupta incelemesi ve çok sayıda parametreyi ikiden fazla seviyede incelemeye imkân sağlamasıdır

$\mathrm{Bu}$ çalışmada Zonguldak (Karadon) taş kömürünün yağ aglomerasyonu davranış1, Taguchi (L16) deneysel tasarım metodu kullanılarak araştırılmıştır. Tasarımda, yağ aglomerasyonunu etkileyen beş adet faktör (gazyağı miktarı, aglomerasyon zamanı, karıştırma hızı, katı konsantrasyonu ve $\mathrm{pH}$ ) ve her bir faktörün dört alt seviyesi incelenmiştir. Deneylerin başarısı aglomeratların $Y K V$ ve kül içerikleri ile değerlendirilmiştir.

\section{MALZEME VE YÖNTEM}

\subsection{Kömür}

Yağ aglomerasyonu deneylerinde, Karadon (Zonguldak) bölgesinden temin edilen taş kömürü kullanılmıştır. Kömür numunesi laboratuvarda bulunan çeneli kırıcı ile kırıldıktan sonra çelik bilyalı değirmen ile öğütülerek deneylere uygun boyutta $(-212 \mu \mathrm{m})$ hazırlanmıştır. Kömür numunesinin tane boyut dağılımı belirlenmiş ve Şekil 1'de verilmiştir. Şekil 1'den tanelerin \%80'inin geçtiği elek açıklığı olan $\mathrm{d}_{80}$ değeri $122 \mu \mathrm{m}$ olarak tespit edilmiş ayrıca kömürün kül içeriğinin ise \%14,6 olduğu saptanmıştır.

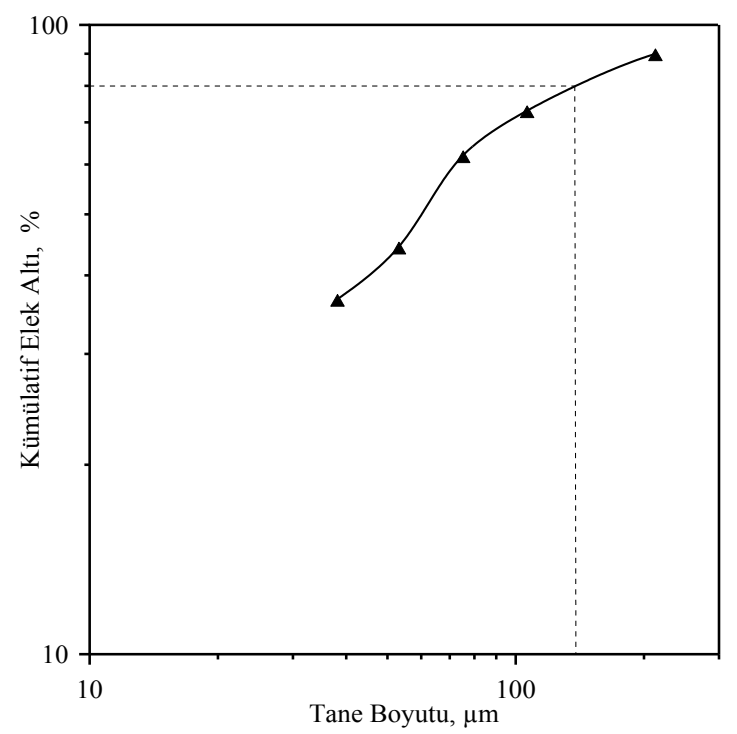

Şekil 1. Kömür numunesinin tane boyut dağılımı

\subsection{Yağ Aglomerasyonu Deneyleri}

Yağ aglomerasyonu deneyleri, içerisinde dört adet bariyer bulunan $400 \mathrm{~cm}^{3}$ hacmindeki deney kabında gerçekleştirilmiştir. Uygun miktarda kömür numunesi tartılarak $300 \mathrm{~cm}^{3}$ hacmindeki su ile 2 dakika süreyle karıştırılmıştır. İyi bir dispersiyonun sağlanmasından sonra süspansiyonun $\mathrm{pH}$ '1 istenen değere hidroklorik asit (HCl) veya sodyum hidroksit $(\mathrm{NaOH})$ ile ayarlanmıştır. $\mathrm{Bu}$ işlem, 5 dakika'lık bir sürede gerçekleştirilmiş ve süspansiyonun $\mathrm{pH}$ değeri, deney sonuna kadar kontrol edilerek sabit 
tutulmuştur. pH ayarlaması sonrasında sisteme gazyağı ilave edilmiş ve belirlenen aglomerasyon süresi sonunda sistem durdurulmuştur. Deneyler sonrasında elde edilen aglomeratlar, test eleği (212 $\mu \mathrm{m})$ ile kazanılmış ve musluk suyu ile yıkanarak aglomera olmayan kısımdan ayrılması sağlanmıştır. Filtre kâğıdında süzüldükten sonra etüvde kurutulan aglomeratlar tartılarak ağırlıkları tespit edilmiş ve kül içerikleri belirlenerek aşağıdaki eşitlikte verilen formül ile yanabilir kısım verimi hesaplanmıştır.

$Y K V, \%=\frac{\mathrm{A}\left(100-A_{\mathrm{kül}}\right)}{\mathrm{B}\left(100-B_{\text {kül }}\right)} x 100$

Burada, $A$ aglomerat yüzdesi; $A_{\text {kül }}$ aglomerat kül içeriği; $B$ besleme yüzdesi; $B_{k u ̈ l}$ besleme kül içeriğidir.

\subsection{Taguchi metodu ile Deney Tasarımı}

Taguchi metodu bir tür kesirli faktöriyel tasarımdır. $\mathrm{Bu}$ tasarım ile yukarıda da ifade edildiği gibi deneylerin tüm kombinasyonlarının denenmesi yerine ortogonal dizinleri yardımıyla sadece bir k1smı yapılmakta ve en iyi performans karakteristiğini veren faktör seviyeleri bulunabilmektedir. Ortogonal dizinler, bir say1 matrisi olarak ifade edilmekte olup her sütun, seçilen faktörlerin seviyelerini gösterirken her satır ise dikkate alınan faktörleri ifade etmektedir. Bu çalışmada da kullanılan $\mathrm{L}_{16}\left(4^{5}\right)$ ortogonal dizisi (5 parametreli ve 4 seviyeli) Çizelge 1 'de görülmektedir. Çizelge 1'de verilen P1, P2, P3, P4 ve $\mathrm{P} 5$, seçilen parametreleri gösterirken her bir satırdaki rakamlar ise parametrelerin seviyelerini ifade etmektedir. Normalde bu 4 seviyeli 5 parametrenin etkilerini tam olarak belirleyebilmek için çok fazla sayıda $\left(4^{5}=1024\right.$ adet $)$ deney yapılması gerekirken Taguchi deney tasarım matrislerindeki ortogonal dizinlerin kullanması ile yalnızca 16 deney yapılmakta böylece hem zaman hem de maliyet açısından büyük avantaj sağlanmaktadır [16].

$\mathrm{Bu}$ metotta oluşturulan tasarımdan elde edilen sonuçlar, sinyal/gürültü $(S / G)$ oranına dönüştürülmekte ve hedeflenen değerin 'en küçük/en iyi’ veya 'en büyük/en iyi’ olmasına göre iki farklı $S / G$ formülü kullanılmaktadır. Bu çalışmada hedeflenen en yüksek $Y K V$ değeri için en yüksek en iyi durumunu veren $S / G$ oranı, Eşitlik 2 'de verilmiştir.

$\frac{\mathrm{S}}{\mathrm{G}}=-10 \log \left[\frac{1}{\mathrm{n}} \sum\left(\frac{1}{\mathrm{YKV}_{\mathrm{i}}}\right)^{2}\right]$

Burada, $n$ tekrarlanan deney sayısını; $Y K V_{i}$ ise $i$ 'nci tekrarlanan deneyden elde edilen yanabilir kısım verimini göstermektedir. $\mathrm{Bu}$ çalışmada her bir deney iki kez tekrarlanmıştır. Yağ aglomerasyonu deneylerinde seçilen parametreler ve seviyeleri Çizelge 2'de verilmiştir.

Çizelge 1. Ortogonal dizin $\mathrm{L}_{16}\left(4^{5}\right)$

\begin{tabular}{|c|ccccc|}
\hline \multirow{2}{*}{ Deney no } & \multicolumn{5}{|c|}{ Parametreler ve Seviyeleri } \\
\cline { 2 - 6 } & P1 & P2 & P3 & P4 & P5 \\
\hline 1 & 1 & 1 & 1 & 1 & 1 \\
2 & 1 & 2 & 2 & 2 & 2 \\
3 & 1 & 3 & 3 & 3 & 3 \\
4 & 1 & 4 & 4 & 4 & 4 \\
5 & 2 & 1 & 2 & 3 & 4 \\
6 & 2 & 2 & 1 & 4 & 3 \\
7 & 2 & 3 & 4 & 1 & 2 \\
8 & 2 & 4 & 3 & 2 & 1 \\
9 & 3 & 1 & 3 & 4 & 2 \\
10 & 3 & 2 & 4 & 3 & 1 \\
11 & 3 & 3 & 1 & 2 & 4 \\
12 & 3 & 4 & 2 & 1 & 3 \\
13 & 4 & 1 & 4 & 2 & 3 \\
14 & 4 & 2 & 3 & 1 & 4 \\
15 & 4 & 3 & 2 & 4 & 1 \\
16 & 4 & 4 & 1 & 3 & 2 \\
\hline
\end{tabular}

\section{BULGULAR VE TARTIŞMA}

\subsection{Deney Tasarımı}

Taguchi L16 deney tasarım planı ile belirlenmiş olan her bir testin parametreleri, bu deneylerden elde edilen $Y K V$ değerleri ile birlikte $S / G$ oranları Çizelge 3'de verilmiştir. Çizelge 3'den görüldüğü gibi $4,7,9,10,11,12$ ve 14 no'lu deneylerde başarılı bir yağ aglomerasyonu işlemi gerçekleşmemiş, dolayısıyla aglomerat kazanımı olmadığından $Y K V_{1}$ ve $Y K V_{2}$ değerleri hesaplanamamıştır. 
Çizelge 2. Parametreler ve seviyelerine göre değerleri

\begin{tabular}{|clcccc|}
\hline Parametre & Tanım & Seviye 1 & Seviye 2 & Seviye 3 & Seviye 4 \\
\hline $\mathrm{A}$ & Gaz yağı miktarı, g/dm & 2,63 & 7,90 & 1,32 & 5,27 \\
$\mathrm{~B}$ & Aglomerasyon süresi, dak & 5 & 10 & 15 & 20 \\
$\mathrm{C}$ & Karıştırma hızı, dev/dak & 500 & 1000 & 1500 & 2000 \\
$\mathrm{D}$ & Katı kons. g/dm & 3,33 & 10,00 & 16,67 & 23,33 \\
$\mathrm{E}$ & $\mathrm{pH}$ & 3 & 5 & 7 & 10 \\
\hline
\end{tabular}

Çizelge 3. Taguchi $L 16$ deney tasarımı ve her bir testin $S / G$ oranları

\begin{tabular}{|cccccccccc|}
\hline Deneyler & $\mathrm{A}$ & $\mathrm{B}$ & $\mathrm{C}$ & $\mathrm{D}$ & $\mathrm{E}$ & $Y K V_{1}$ & $Y K V_{2}$ & $Y K V_{\text {ort }}$ & $S / G$ \\
\hline Test 1 & 2,63 & 3 & 500 & 3,33 & 3 & 38,6 & 35,9 & 37,25 & 31,41 \\
Test 2 & 2,63 & 5 & 1000 & 10,00 & 5 & 96,1 & 92,3 & $\mathbf{9 4 , 2 0}$ & $\mathbf{3 9 , 4 8}$ \\
Test 3 & 2,63 & 10 & 1500 & 16,67 & 7 & 26,1 & 26,4 & 26,25 & 28,38 \\
Test 4 & 2,63 & 15 & 2000 & 23,33 & 10 & 0,00 & 0,00 & 0,00 & 0,00 \\
Test 5 & 7,90 & 3 & 1000 & 16,67 & 10 & 86,3 & 82,9 & 84,6 & 38,54 \\
Test 6 & 7,90 & 5 & 500 & 23,33 & 7 & 71,5 & 68,3 & 69,90 & 36,88 \\
Test 7 & 7,90 & 10 & 2000 & 3,33 & 5 & 0,00 & 0,00 & 0,00 & 0,00 \\
Test 8 & 7,90 & 15 & 1500 & 10,00 & 3 & 69,7 & 70,2 & 69,95 & 36,90 \\
Test 9 & 1,32 & 3 & 1500 & 23,33 & 5 & 0,00 & 0,00 & 0,00 & 0,00 \\
Test 10 & 1,32 & 5 & 2000 & 16,67 & 3 & 0,00 & 0,00 & 0,00 & 0,00 \\
Test 11 & 1,32 & 10 & 500 & 10,00 & 10 & 0,00 & 0,00 & 0,00 & 0,00 \\
Test 12 & 1,32 & 15 & 1000 & 3,33 & 7 & 0,00 & 0,00 & 0,00 & 0,00 \\
Test 13 & 5,27 & 3 & 2000 & 10,00 & 7 & 84,5 & 82,5 & 83,5 & 38,43 \\
Test 14 & 5,27 & 5 & 1500 & 3,33 & 10 & 0,00 & 0,00 & 0,00 & 0,00 \\
Test 15 & 5,27 & 10 & 1000 & 23,33 & 3 & 93,1 & 93,2 & 93,15 & 39,38 \\
Test 16 & 5,27 & 15 & 500 & 16,67 & 5 & 77,5 & 80,0 & 78,75 & 37,92 \\
\hline
\end{tabular}

Taguchi deney tasarımı kullanılarak gerçekleştirilen deneyden elde edilen aglomeratların boyutları da farklılık göstermektedir. Şekil 2'de Test 2 ve Test 16'dan kazanılan aglomeratların görüntüleri verilmiştir. En yüksek $Y K V$ ve $S / G$ oranının elde edildiği deney olan Test 2'den kazanılan aglomeratların ortalama boyutu $1 \mathrm{~mm}$ ve $Y K V$ değeri \%94,2'dir. Test 16 ise en büyük aglomerat boyutunun elde edildiği deney olup ortalama aglomerat boyutu $5-7 \mathrm{~mm}, Y K V$ ve $S / G$ oran 1 ise sirasiyla $\% 78,75$ ve 37,92'dir. Her iki deneyin gerçekleştirildiği şartlar incelendiğinde (Çizelge 3), parametreler arasındaki belirgin farkın aglomerasyon hizı ve zamanı olduğu görülmektedir. 16 nolu deneyde, aglomerasyon süresinin artmasıyla yüzeyleri yă̆ ile kaplanmış kömür tanelerinin birbirleriyle temas süreleri artmış ve bu da aglomeratların boyutlarının daha büyük olmasına yol açmıştır. Karıştırma hızının da düşük olmasıyla bu durum daha da olanaklı hale gelmiştir. Aglomeratların boyutlarının bu denli büyük olmasının nedeninin düşük hızda uzun süreli karıştırmadan kaynaklandığı söylenebilir. Ancak aglomerat boyutunun büyük olmasıyla kalitesinin de arttığını söylemek doğru olmaz. Çünkü uzun süreli karıştırma, kül yapıcı inorganik maddelerin aglomeratların içerisinde sıkışmasına neden olarak aglomerat boyutunu büyütmesine karşın kül içeriğini arttırarak $Y K V$ 'i dolayısıyla kalitesini de düşürmektedir [17-19]. 
Taguchi Deneysel Tasarım Metodu Kullanılarak Karadon (Zonguldak) Kömürünün Yağ Aglomerasyonu Davranışının İncelenmesi

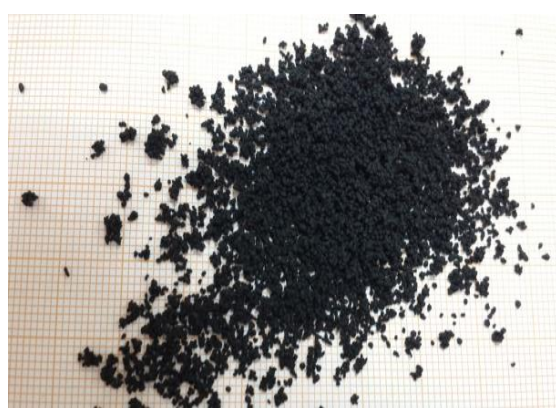

Test 2

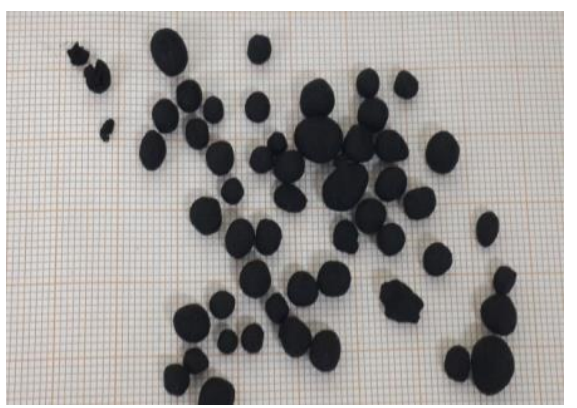

Test 16

Şekil 2. Test 2 ve Test 16'dan elde edilen aglomeratların görüntüsü

\subsection{Anlam Analizi (ANOM)}

Taguchi tasarımı ile gerçekleştirilen deneylerin optimum koşulları, anlam analizi için her bir parametrenin $(P)$ belirli seviyesinin $(i)$ ortalama $S / G$ oranı aşağıdaki eşitlik yardımıyla belirlenerek değerlendirilmiştir.

$\mathrm{M}_{i}^{P}=\frac{1}{\mathrm{n}_{\mathrm{Pi}}} \sum_{\mathrm{j}=1}^{\mathrm{n}_{\mathrm{Pi}}}\left[\left(\frac{\mathrm{s}}{\mathrm{G}}\right)_{i}^{P}\right]_{\mathrm{j}}$

Burada; $n_{P i}$ Çizelge 3'teki $i$ 'nci seviyedeki $P$ parametresinin görülüm sayısını gösterirken $\left(\frac{\mathrm{S}}{\mathrm{G}}\right)_{\mathrm{i}}^{\mathrm{P}}$, $P$ parametresinin $i$ seviyesindeki $S / G$ oranı ve $\left[\left(\frac{\mathrm{S}}{\mathrm{G}}\right)_{i}^{P}\right]_{\mathrm{j}}$ ise Çizelge 3'teki j'nci görülümünü göstermektedir. Benzer şekilde tüm parametrelerin belirli seviyelerindeki $\mathrm{S} / \mathrm{G}$ oranlarının anlamlı tepkisi hesaplanmıştır. $M_{i}^{P}$, her bir parametrenin her bir seviyesinin bağımsız tepkisini göstermekte olup Çizelge 4'te verilmiştir. Parametrelerin seviyeleri içerisinde en büyük $S / G$ oranını veren optimum sonuçlar, koyu renkte belirtilmiştir. Optimizasyon çalışmalarından elde edilen sonuçlara göre doğrulama deneyi yapılmış ve bu deneyden elde edilen $Y K V$ ile $S / G$ oranı, yeniden hesaplanarak Test 2 ile karşılaştırmalı olarak Çizelge 5'te verilmiştir.
Çizelge 4. $S / G$ oranlarının ve $Y K V$ 'nin tepkisi

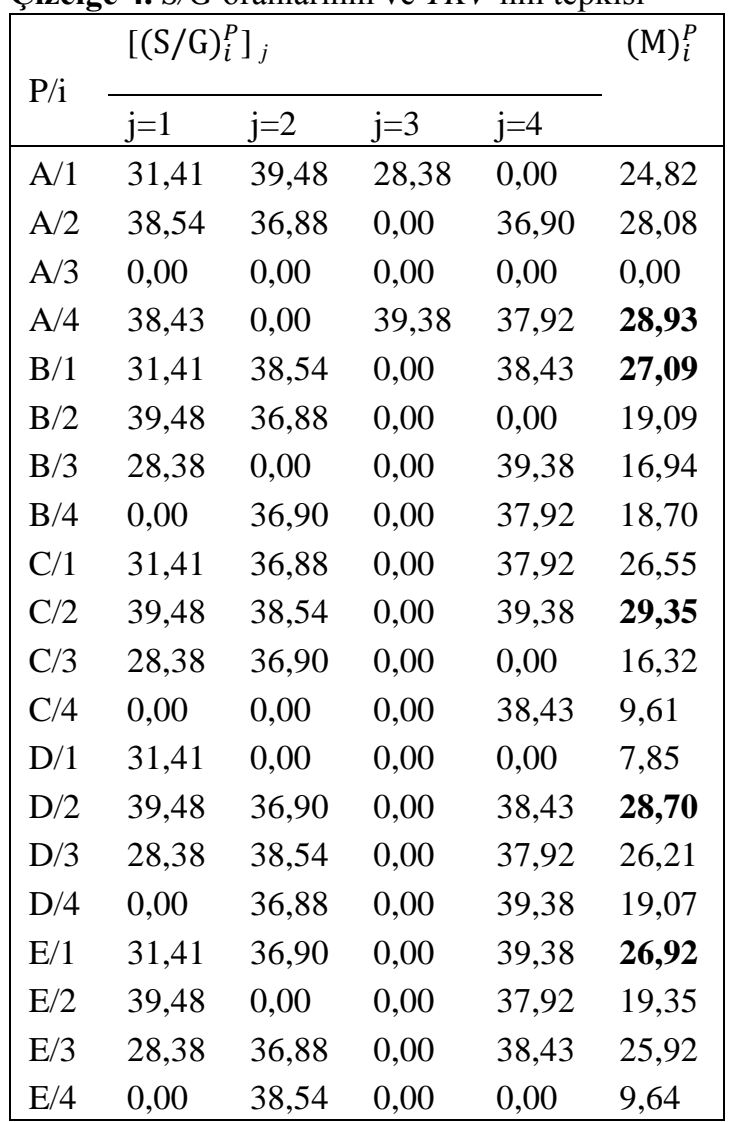

Çizelge 5. Yağ aglomerasyonu için optimum deney şartları

Çizelge 5. Yağ aglomerasyonu için optimum deney şartlar1
\begin{tabular}{|lccccccccc|}
\hline & $\mathrm{A}$ & $\mathrm{B}$ & $\mathrm{C}$ & $\mathrm{D}$ & $\mathrm{E}$ & $\mathrm{YKV}_{1}$ & $\mathrm{YKV}_{2}$ & $\mathrm{~S} / \mathrm{N}$ \\
\cline { 2 - 9 } Test 2 & 2,63 & 5 & 1000 & 10,00 & 5 & 96,1 & 92,3 & 39,48 \\
Optimizasyon & 5,27 & 3 & 1000 & 10,00 & 3 & 88,76 & 89 & 38,98 \\
\hline
\end{tabular}


Optimizasyon çalışmaları ile Test 2'nin deneysel şartları karşılaştıııldığında, karıştırma hızı ve katı konsantrasyonunun değişmediği ancak yağ miktarının optimizasyon deneyinde iki katı olduğu, aglomerasyon zamanının daha kısa ve $\mathrm{pH}$ değerinin daha düşük olduğu göze çarpmaktadır. $Y K V$ değerleri ve $S / G$ oranları karşılaş̧ırııldığında ise Test 2'nin sonuçlarının daha iyi olduğu görülmektedir. Taguchi deney tasarımını kullanarak yapılan çalışmalarda amaç optimal sonuçlara ulaşmaktır. Bu sonuç, bazen tasarımda verilen mevcut deneylerden herhangi birisi olabilirken bazen de tasarımın önerdiği deney sonucu olabilmektedir [20]. Bu nedenle doğrulama deneyinin yapılması gerekmektedir. Bu çalışmada ise tasarımda yapılan deneylerden Test 2 ile optimum sonuçlar elde edilmiştir.

\section{SONUÇLAR}

Karadon (Zonguldak) kömürünün yağ aglomerasyonu davranışı, Taguchi tasarım metodu kullanılarak araştırılmıştır. Aglomerasyon deneyleri ile elde edilen aglomeratların $Y K V$ değerleri $S / G$ oranına dönüştürülerek anlam analizi gerçekleştirilmiş ve optimizasyon sonrası yapılan doğrulama deneyi ile Test 2'den elde edilen sonuçların optimum olduğu anlaşılmıştır. Ulaşılan optimum koşullar; gazyağı konsantrasyonu, aglomerasyon zamanı karıştırma hızı, katı konsantrasyonu ve $\mathrm{pH}$ için sırasıyla $2,63 \mathrm{~g} / \mathrm{dm}^{3}$, 5 dak, $1000 \mathrm{dev} / \mathrm{dak}, 10 \mathrm{~g} / \mathrm{dm}^{3}$ ve 5 olarak belirlenmiştir. $\mathrm{Bu}$ şartlarda yapılan yağ aglmerasyonu sonrası elde edilen agomeratların $Y K V$ değerinin ortalama $\% 94,2$ ve ortalama aglomerat boyutunun ise $1 \mathrm{~mm}$ olduğu tespit edilmiştir. Yine Test 16 ise belirlenen şartlarda en büyük aglomerat boyutu (ortalama 5-7 $\mathrm{mm}$ ) elde edilmesine rağmen $Y K V$ değerinin $\% 78,75$ olduğu anlaşılmıştır. Sonuç olarak Taguchi deneysel tasarımının kullanılmasıyla geleneksel yöntemlere kıyasla daha az sayıda deney ile farklı şartlarda deney yapmak ve optimum sonuçlara ulaşmak mümkündür.

\section{KAYNAKLAR}

1. Somasundaran, P., 1980. Principles of Flocculation, Dispersion, and Selective Flocculation, In: Fine Particle Processing, P. Somasundaran (ed.), AIME, New York, 947-975.

2. Capes, C.E., Darcovich, K., 1984. A Survey of Oil Agglomeration in wet Fine Coal Processing, Powder Technology, 40, 43-52.

3. Laskowski, J.S., 1992. Oil Assisted Fine Particle Processing, In: Colloid Chemistry in Mineral Processing, J.S. Laskowski and J. Ralston (eds.), Elsevier, New York, 361-394.

4. Yarar, B., 1988. Flotation, In Ullmann's Encyclopedia of Industrial Chemistry, vol. B2(23), VCH, Weinheim, 1-29.

5. Warren, L.J., 1975. Shear Flocculation of Ultrafine Scheelite in Sodium Oleate Solutions, Journal of Colloid and Interface Science, 50, 307-318.

6. Labuschagne, B.C.J., 1986. Relationships Between Oil Agglomeration and Surface Properties of Coal: Effect of $\mathrm{pH}$ and Oil Composition, Coal Preparation, 3, 1, 1-13.

7. Capes, C.E., 1980. Principles and Applications of Size Enlargement in Liquid Systems, Fine Particles Processing, AIME, 2, 1442-1462.

8. Kılınç Aksay, E., Arslan, V., Polat, H., 2010. Toz Kömürlerin Zenginleştirilmesinde Yağ Aglomerasyonu Yöntemi ve Yenilikler, İstanbul Yerbilimleri Dergisi, 23, 2, 97-108.

9. Ünal, İ., Aktaş, Z., Olcay, A., 2000. Bitümlü Kömür ve Linyitin Yağ Aglomerasyonu, Türkiye 12. Kömür Kongresi Bildiriler Kitab1, Zonguldak, 251-260.

10. Aktas, Z., 2002. Some Factors Affecting Spherical oil Agglomeration Performance of Coal Fines, International Journal of Mineral Processing, 65, 177-190.

11. Cebeci, Y., Ulusoy, U., Simsek, S., 2002. Investigation of the Effect of Agglomeration Time, $\mathrm{pH}$ and the Various Salts on the Cleaning of the Zonguldak Bituminous Coal by Oil Agglomeration, Fuel, 81, 1131-1137.

12. Cebeci, Y., 2003. Investigation of Kinetics of Agglomerate Growth in Oil Agglomeration Process, Fuel, 82, 1645-1651. 
Taguchi Deneysel Tasarım Metodu Kullanılarak Karadon (Zonguldak) Kömürünün Yağ Aglomerasyonu Davranışının İncelenmesi

13. Cebeci, Y., Sonmez, I., 2006. Application of the Box-Wilson Experimental Design Method for the Spherical Oil Agglomeration of Coal, Fuel, 85, 289-297.

14. Aslan, N., Unal, I., 2009. Optimization of Some Parameters on Agglomeration Performance of Zonguldak Bituminous Coal by Oil Agglomeration, Fuel, 88, 490-496.

15. Taguchi, G., 1990. Introduction to Quality Engineering, New York, NY: McGraw-Hill Book Co.

16. Şirvanc1, M., 1997. Kalite İçin Deney Tasarımı 'Taguchi Yaklaşımı', İstanbul, Literatür Yayıncilık.

17. Chary, G., Dastidar, M., 2010. Optimization of Experimental Conditions for Recovery of Coking Coal Fines by Oil Agglomeration Technique, Fuel, 89, 2317-2322.

18. Sahinoglu, E., Uslu, T., 2008. Amenability of Muzret Bituminous Coal to Oil Agglomeration, Energy Conversion and Management, 49, 3684-3690.

19. Duzyol, S., 2015. Investigation of Oil Agglomeration Behaviour of Tuncbilek Clean Coal and Separation of Artificial Mixture of Coal-Clay by Oil Agglomeration, Powder Technology, 274, 1-4.

20. Yılmaz, V., Dilipak, H., Sarıkaya, M., Yılmaz, C.Y., Meral, G., 2014. Frezeleme İşlemlerinde Titreşimi ve Yüzey Pürüzlülüğünü Etkileyen Parametrelerin Optimizasyonu, S.D.Ü. Teknik Bilimler Dergisi, 4, 1, 37-44. 